\title{
Applying Augmented Reality to Preserving Industrial Heritage
}

\author{
Tessa Morrison \\ School of Architecture \& Built Environment \\ The University of Newcastle, Australia, 2308 \\ Tessa.morrison@newcastle.edu.au
}

\author{
Ning Gu \\ School of Architecture \& Built Environment \\ The University of Newcastle, Australia, 2308 \\ ning.Gu@newcastle.edu.au
}

\author{
Nicholas Foulcher \\ School of Architecture \& Built Environment \\ The University of Newcastle, Australia, 2308 \\ c3058689@uon.edu.au
}

\begin{abstract}
Preserving cultural heritage of industrial sites has become a political issue in Australia and elsewhere with the closure of many manufacturing and engineering based industries, the needed modernization of existing industrial sites and the spread of housing development into areas that have traditionally been preserved for industrial use. The size of these sites makes it difficult to preserve them and the preservation of most cultural heritage becomes partial, such as displaying industrial machinery in parks well away from their original position and context. Australia is losing much of its important industrial cultural heritage. Newcastle, Australia, is the sixth largest city in Australia and is the largest coal export port in the world. Its entire history of European settlement, since 1801, was built on industry. Its history is a cycle of booms and busts with a constantly changing industrial landscape. The paper examines an alternative and holistic method of preserving the cultural heritage of industrial sites, which would otherwise has been lost, using augmented reality and mobile technologies. The city of Newcastle is presented as a case study.
\end{abstract}

Newcastle, Australia. Augmented Reality. Industrial Heritage. Mobile Technology.

\section{INTRODUCTION}

In September 1797, first lieutenant John Shortland while on his way to Port Stephens, (150 kilometres north of Sydney, Australia) in pursuit of some runaway convicts, entered an estuary of a river. In a letter to his father he claimed that it was a 'very fine coal river' in which vessels from 60 to 250 tons would be able to load with great ease (Shortland, 1915, 481). He named the river Hunter after the current Governor of the Colony. However, it was another four years and a change of Governor before Governor Philip King sent LieutenantColonel William Paterson to report on the prospects of the coal deposits, the river and the surrounds.

Paterson arrived at the estuary of the River, which he renamed Coal River, on June 14, 1801. He was overwhelmed by the volume of visible coal deposits, the estuary became known as Coal Harbour.There Paterson landed on an island which he named Coal Island, now called Nobbys. Paterson sent some colliers to work on the coal deposits, to examine the quantity and quality of the coal, on the South side of the Coal Harbour. He called it Colliers' Point suggesting that this was the first place in Coal Harbour where a coal pit was sunk. In his report to Governor King, Paterson claimed that
I am of opinion that [the] Government might derive many advantages by forming a small settlement at this place. In the $1^{\text {st }}$ instance the coals are a principle object. $2^{\text {nd }}$ boiling salt, which could be done with little labour. $3^{\text {rd }}$ burning shells that are here in great abundance. Besides, salting of fish might be carried on with considerable benefit if some industrious fisherman could be found for that purpose, as the fish are plentiful and good (Paterson, 1898, 449).

The abundance of coal in Coal Harbour was an extremely beneficial asset to the fledgling colony, not only for its own use but to trade for needed supplies with other Colonies, such as the Cape of Good Hope. In addition, no limestone had been found in the Colony thus the burning of shells, which were also abundant, became necessary for the production of lime for mortar and whitewashing buildings. Both the burning of shells and the production of salt required a lot of fuel. This made Coal Harbour the perfect place for these industries. These industries were also labour intensive.

In the early nineteenth century there was only one source of labour in the Colony - convict labour - at this time there were few free settlers and most of the settlers were not of the labouring class. However, Coal Harbour was isolated by land, as it was extremely inhospitable land, and only assessable by sea. The port that was established at Coal Harbour was for the most incorrigible convicts mostly political prisoners; it was a place of 
punishment and incredible hardship, made even harder by working in chained-gangs. Originally the port was called Kings Town by the commander of the settlement after the Governor; but Governor King claimed that the settlement would be more appropriately named Newcastle after Newcastle upon Tyne.

The Newcastle coal, salt, lime and cedar, from the surrounding forests, were shipped to Sydney and what was not needed for the Colony's own consumption was exported. Governor King reported to the Duke of Portland in London "This being the first natural produce of the Colony that has tended to any advantage (King, 1898, 477)." Newcastle was reserved for the Government. In 1813 , the port of Newcastle was opened for nonGovernment shipping (Ellis, 2010, 441); however, is still remained Government land. The coal mines of Newcastle had been the exclusive property of and administered by the Crown, until the 1833 when The Australian Agricultural Company took over the coal monopoly from the Government, with promises of unlimited labour. The demands for labour grew but transportation of convicts to New South Wales had been terminated in 1840; thus the supply of convict labour was diminishing. By 1850s the industries of Newcastle were growing rapidly and the monopoly of Australian Agricultural Company had been withdrawn by the Government which saw the industries in Newcastle expand.

The city of Newcastle was becoming the major industrial city in New South Wales; yet all the produce was still being shipped to Sydney. It was not until 1845 that the Port of Newcastle became a free trading port which could export its produce directly to anywhere in the world. The city grew around the coal pits and other industries. From the beginnings of the settlement which was made up of 40 chained convicts and military escort of 12 soldiers, it is now the sixth largest city in Australia and the largest coal export port in the world.

Many industries are clustered on the north-west side of the Port of Newcastle including the coal loaders that operate 24-hours per day. There is a constant change in the industrial landscape with either modernisation of some industries and the demise of other industries. Other areas where coal pits dominated the landscape have become suburbs where industry no longer exists. Not all the important industries that have shaped Newcastle have survived. The State Dockyard which opened in 1942 and closed in 1987 and BHP steelworks opened in Newcastle in 1911 and closed in 1999. Both employed large workforces (the steelworks employed up to 13000 workers). The industrial port of Newcastle has gone through phases of change and redevelopment and this makes any preservation of industrial sites problematic as new industries and structures replace the old, or industrial sites are transformed into recreation or housing sites.

\section{CURRENT PRESERVATION OF THE INDUSTRIAL HERITAGE}

Attempts to preserve industrial cultural heritage have been partial and not always successful. The Newcastle Museum has an exhibition gallery on the 'Newcastle Story' which concentrates on the natural environment, early Aboriginal life, a brief summary of Newcastle's history, and its people. However, although the exhibition mentions the industry of Newcastle its main display is separate from the 'Newcastle Story' gallery. One exhibition gallery is dedicated to BHP Steel, which is a small part of Newcastle's industrial history. The exhibition contains objects, interactive exhibits, images, videos, and sound clips while the exhibition is informative and interesting part of Newcastle's industrial heritage, it is disconnected and completely out of context. Outside of the museum is a piece of industrial machinery which has been restored and is now used as a signpost for the museum (see Figure 1). Whilst this is an interesting architectural use of this piece of machinery it does little to preserve the heritage that surrounds its history. From the exhibits the visitor to the museum would have very little idea of the importance of industry to Newcastle's development and planning.

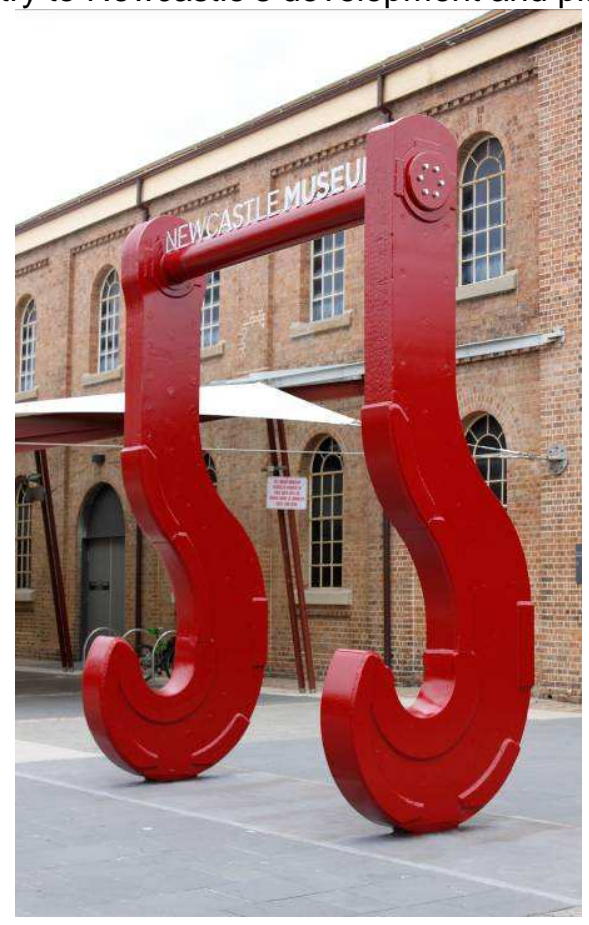

Figure 1: Industrial equipment used as a sign post

There have been some very successful international examples for preservation of industrial sites. Zollverein industrial complex in Land Nordrhein-Westfalen, Essen, Germany consists of 
the complete infrastructure of a historical coalmining site, it has some industrial buildings of outstanding architectural merit. The mines were closed in 1993 after 150 years of production. It is now open to the public and is a UNESCO World Heritage site (Figure 2). The visitor can take a tour of the old industrial buildings, there is a museum which explains the history and workings of the mine and the surrounding land has been transformed into a park where concerts are held. It is an extremely successful preservation which preserves both the building and its history, and captures the public's imagination. Some preservations have preserved the building and surrounds but the building's function has been changed to get greater utility from these massive buildings. The Jahrhunderthalle (Century Hall) at Bochum, Germany was built in 1902 (Figure 3), formerly the gas power station of the Bochum Company, it has now become an extraordinary festival hall. Not far from the city centre it has become a vital part of the city's cultural events. Tate Modern, formally Bankside Power Station in central London, originally designed by the architect Sir Giles Gilbert Scott and built in two stages in the mid-twentieth century, is now an important landmark of London and a significant international gallery of Modern art. As impressive as these restorations are they are very rare and often require significant input from governments with the reinforcement of specific urban and economic policies.

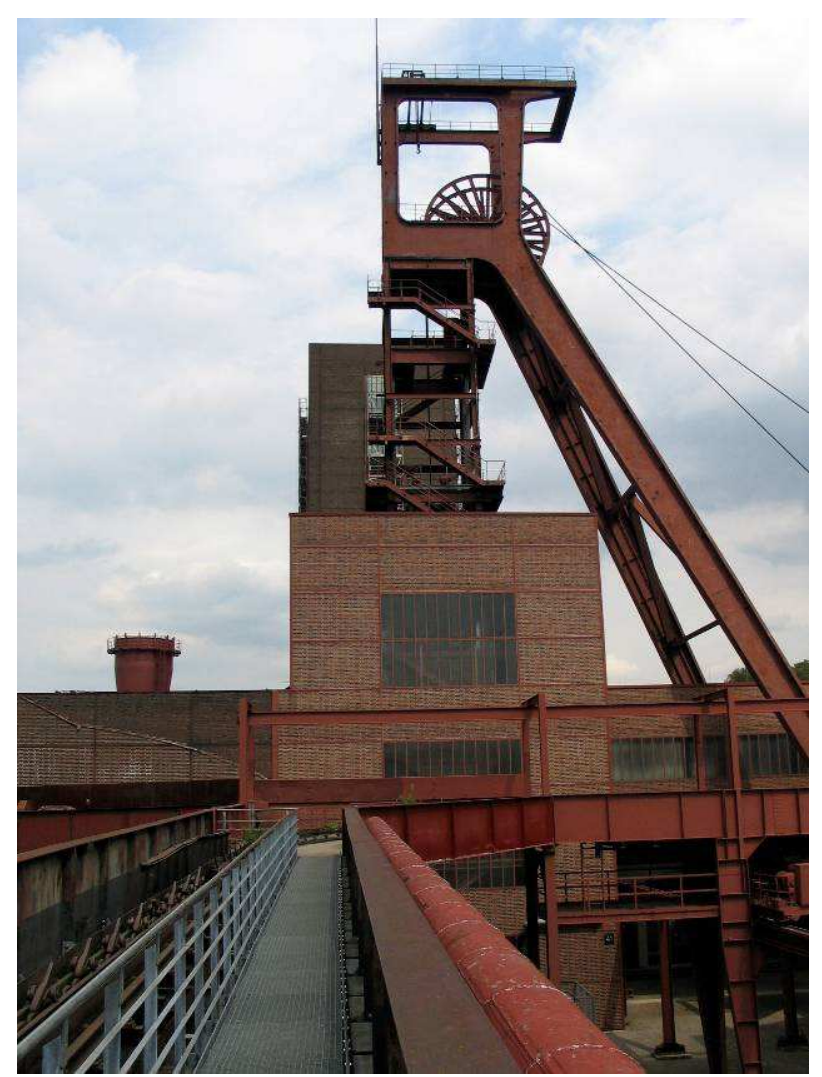

Figure 2: Zollverein industrial complex
This preservation of these sites is only possible because its mines or the industry had out lived their usefulness and were no longer commercially viable. However, many industrial sites remain viable and productive, like Newcastle and many others around the world, and a physical restoration in situ is impossible.

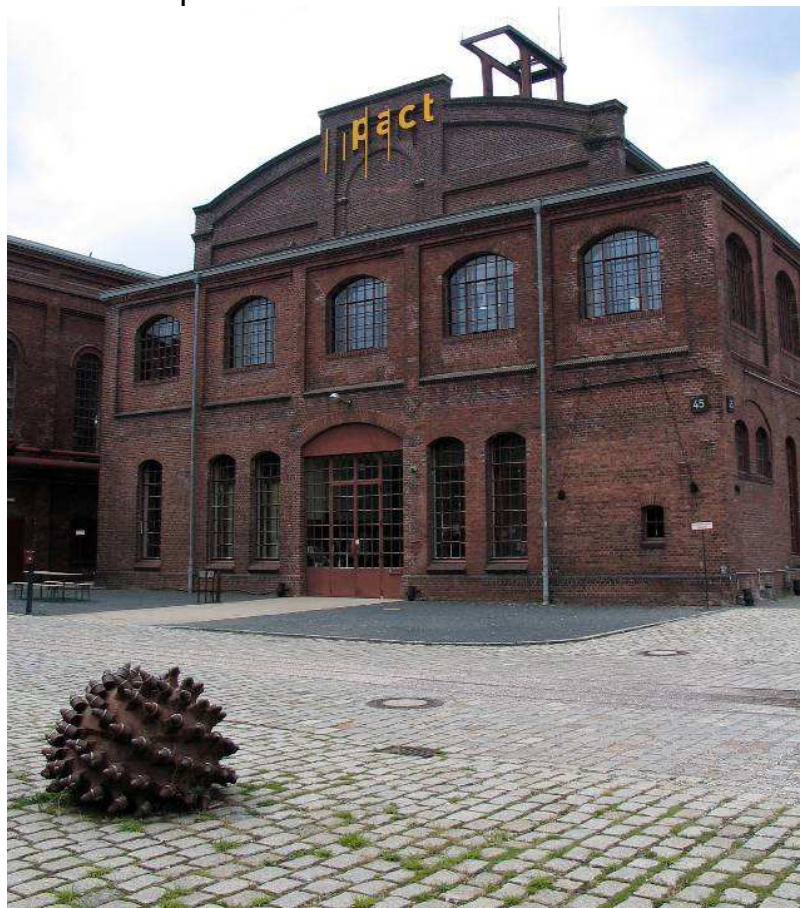

Figure 3: Zollverein industrial complex

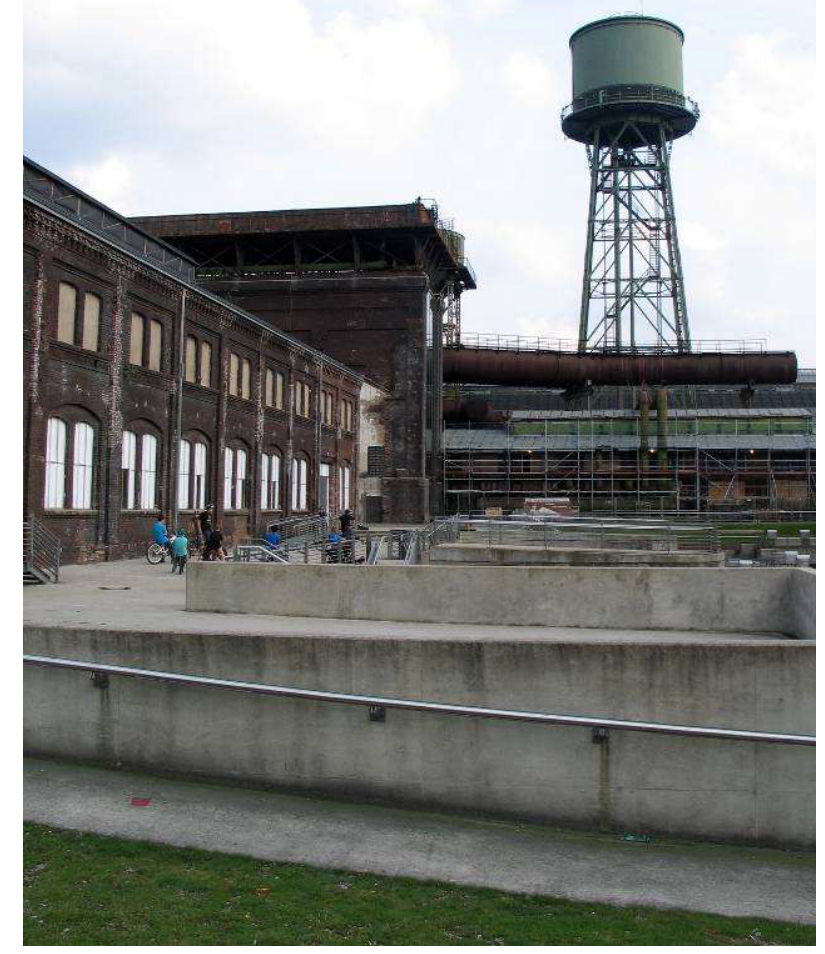

Figure 4: Jahrhunderthalle (Century Hall) at Bochum 


\section{THE NEWCASTLE PROJECT}

The question of 'how do we preserve the cultural heritage of industrial sites?' has become an increasingly important issue in Australia and throughout the world. The industrial landscape is either rapidly changing or disappearing and only a small fraction of it is being preserved. Whilst the industry remains viable and profitable, preservation is not always considered. It is the scale of the sites that makes it difficult to preserve them even partially. The main aim of this project is to develop a formal framework for an alternative way of conserving cultural heritage of industrial sites, through virtual technologies such as augmented reality $(A R)$ and mobile technologies.

As developments in digital technology exponentially increase, so do the opportunities for exploring the application of the ecology of digital mediums. The current technological climate, driven by a thriving social networking movement, makes it possible for both users and researchers to be directly involved in contributing layers of meta-data to a constantly evolving virtual urban topography. Through the lens of the current entry-level smart phone, a user is exposed to an extra dimension of information, which runs in parallel to the physical world. If this extra dimension is applied to applications of preserving the cultural heritage of a place, the historical value and identity can be virtually reborn and conserved for future generations. This is made possible by the continuing advances in augmented reality applications (Morrison \& Gu, 2011); this process of exploration in a city is linked with a ubiquitous platform of multimedia content that has the potential to spark a rebirth of an architecture of the past, for the future.

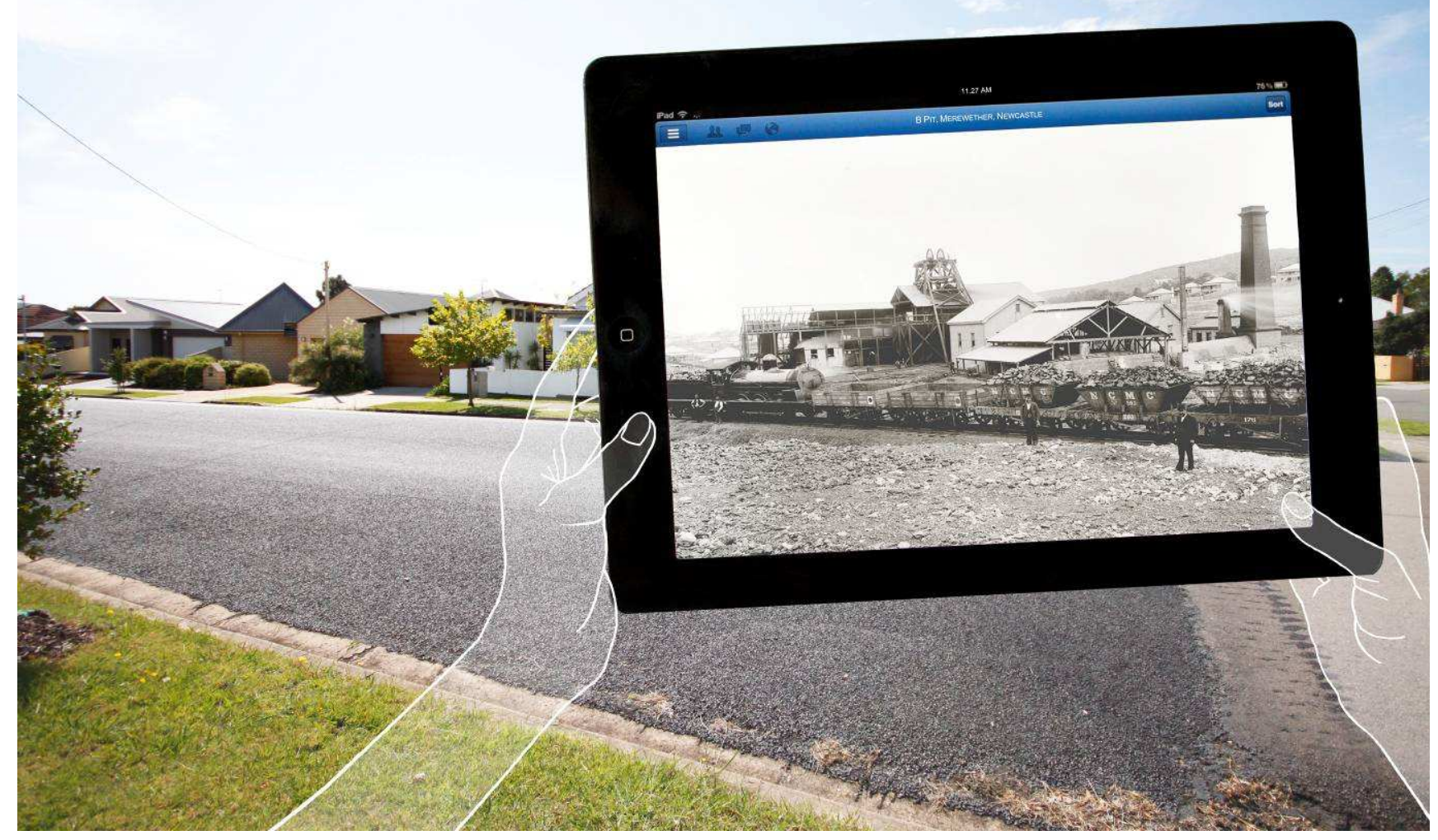

Figure 5: Photoshop mock-up of a coal pit at Merewether, now a suburb of Newcastle with no industry 


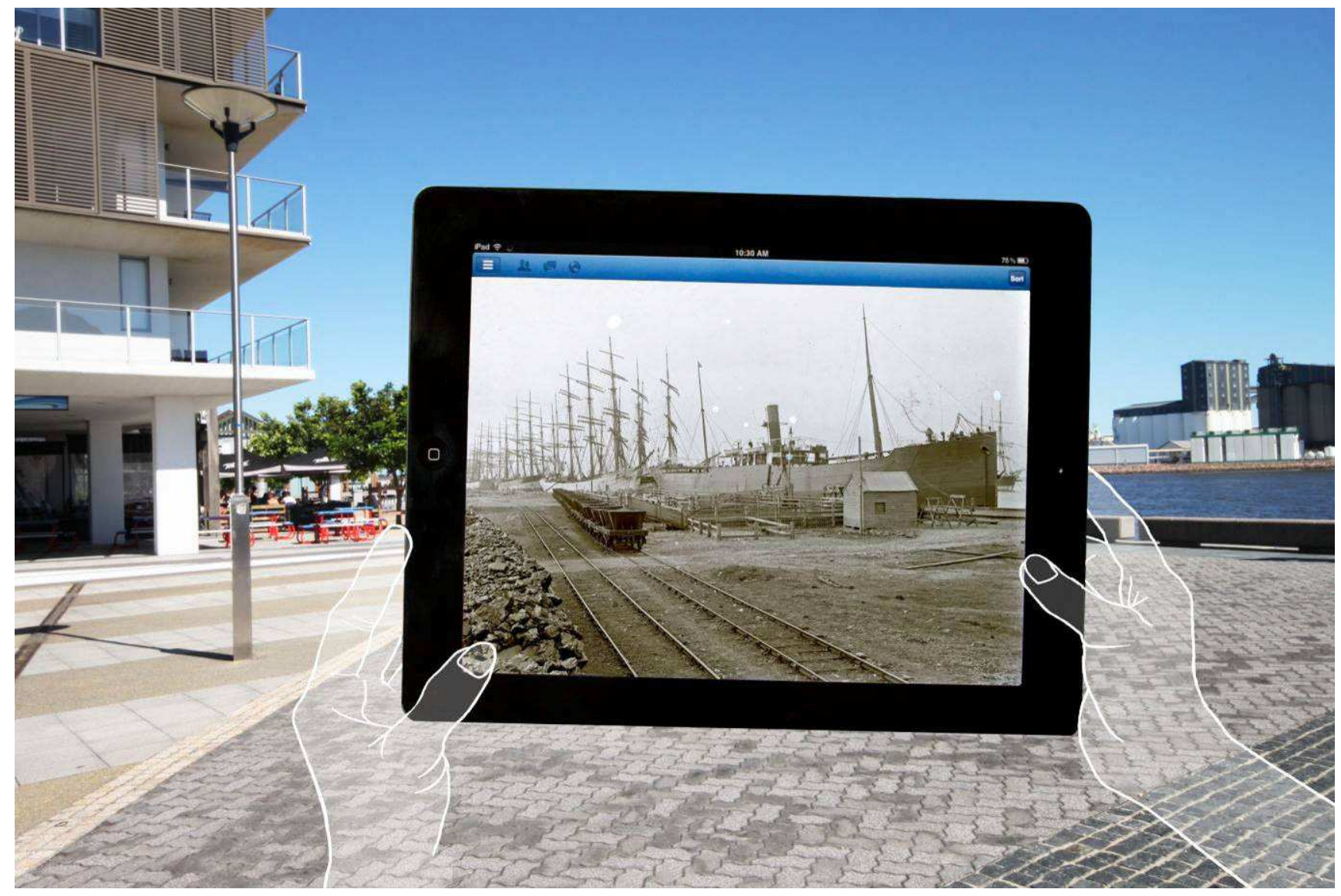

Figure 6: Loading coal 1900, the modern image shows industry on the north side of the harbour while the south side is a harbour promenade lined with cafes and restaurants

The project builds on existing AR and mobile technologies (Portales, 2009), and the concept of the ubiquitous city (Burns, 2006). The concept of the ubiquitous city is to link all urban systems through information technologies and to effectively inform and connect people. Shared data and computers are built into the urban infrastructures such as shops, streets and office buildings and this information is accessed intuitively through mobile and other tangible devices (Gervais \& el al, 2007). Users can immediately get information on transport, entertainment, reviews and street directions, which interacts and directs them for further use. South Korea is currently exploring this concept and the supporting technologies in its pioneering cities. For example, they are currently building New Songdo City which will link all information systems to all houses as well as shops, streets and offices. While the technology is currently being trialled for social, entertainment and convenience purposes, this research project refocus and further this approach into a cultural and societal one.
In the long-term this research will be presented in two different forms: 1. Through a typical AR interface enhanced with additional data capture and analysis applications to present the research and professional communities the detailed and analysed virtual preservation of the cultural heritage of Newcastle industrial sites; 2 . Through the increasingly accessible and popular mobile devices such as an iPhone/iPad to engage the general public enabling their immediate access to key facets of this preservation.

Currently the first prototype is being developed for the mobile devices. After downloading the application onto an iPhone/iPad, when a viewer walks around the city and passes or enters a site that has an industrial history, the viewer will be able to browse the selected historical records in the forms of digital photos and digital models that reflects key facets of the industrial history of this site, through their iPhone/iPad. The selected sites for the current implementation are centred around Newcastle Harbour. In this manner, the public can view the 'past' of the site in situ.

Newcastle has had some significant periods in its development and its extensive photographic 
documentation goes back to the 1860s. The project is currently reconstructing three eras of industrial growth: the 1880s, 1930s and 1950s. The viewer will be able to switch from one era to another viewing the old photographs from each era in situ.

At a deeper level embedded data will present an extra level of information, which can be seen separately or together with the developing factors of the industrial cities. This project is producing a new method of both retaining the cultural heritage, for viewing its changing history and for identifying the changes to sites through time. These factors will be synthesised, mapped and abstracted to form an integrated and multi-dimensional visualisation enhanced with the embedded analysis, which will enable an evaluation and preservation of the economic, political and humanity impact of the industry on the cityscape forming a part of a ubiquitous city prototype with a cultural and societal focus.

\section{WHO WOULD BENEFIT FROM SUCH A PROJECT?}

The project has both public and academic outcomes. Newcastle has a significant tourist industry. Its magnificent beaches and the vineyards of the Hunter Valley are out of sight of the industrial sites yet they were originally industrial sites themselves. For an interested tourist visiting the Newcastle area this interactive $A R$ application would give an insight into the history and development of Newcastle that they would not be able to get with any other media. Even if the same images were in the Museum they would not give the visitor the same depth of understanding as experiencing the image in situ and see the changes through the different eras.

However, the main propose and benefit is for the academic community. This proposal presents an important application of an existing technology through an AR interface enhanced with additional data capture and analysis applications it can be utilized to preserve, analyze and present cultural heritage which would otherwise be lost. The project will be mapping large sections of the city, where the industry no longer exists, and the current industrial area, where industry has existed very early in Newcastle's history. Many areas can be mapped sequentially; which will build a truer perception of the industrial landscape of the era. The embedded data such as data analysis that affect an industrial city, such as the distribution and changes of population, ethnicity, professions, family incomes, political party preferences, urban and transportation patterns, infrastructure building etc., will further understanding of the cultural and societal aspect of the industrial past of the city. These detailed analyses are particular useful for user groups such as heritage conservationists, architects and urban designers, policy makers, economy and sociology researchers. It will present a holistic and new view of the cultural and societal heritage for industrial sites.

\section{CONCLUSION}

Both this project and AR technologies are in their infancy. This technology has great potential to assist as a tool for architectural historians. It brings in a further aspect to the virtual model that promotes understanding in the relationship of the building and the natural or built topologies. Newcastle is an idea city for a case study to test the effectiveness of these technologies to preserve the cultural heritage of industrial sites and of the industrial city. It has a long history of industrialization which had been documented since European settlement: 1) the origins of the city are in industry; 2) it is an evolving industrial city; 3 ) there are copious historic materials available. Newcastle has a rich industrial past worth persevering and the study in this research would make an excellent prototype for the preservation of other industrial sites.

The Newcastle project explores and demonstrates an alternative method for conserving and enhancing industrial heritage through applying $A R$ and mobile technologies. Furthermore, it enhances the traditional preservation method to enable the superimposition of heritage across different eras, as well as preserving the lost heritage through virtual technologies and contextualising them by embedding them in the current physical environment. The significance of the alternative method being proposed, of preserving cultural heritage of these industrial sites, is a retrospective and holistic approach, which will encapsulate the evolution and development of these industrial sites through history.

\section{REFERENCES}

Bruns, F. Wilhelm. (2006) Ubiquitous Computing and Interaction. Annual Reviews in Control 30, no. 2 20513.

Ellis, M. H. (2010) Lachlan Macquarie Angus and Robertson, Sydney.

Gervais, Eric, Hongsheng Liu, Doron Nussbaum, Young-Soo Roh, and Jiehua Yi. (2007) Intelligent Map Agents, An Ubiquitous Personalized Gis. ISPRS Journal of Photogrammetry and Remote Sensing 62, no. 5, 347-65.

King, Philip. (1898) Letter the Duke of Portland dated 21 August 1801 in Historical Records of New South Wales: Volume IV Hunter and King, (William Applegate Gullick, Government Printer, Sydney, 477. Morrison, Tessa, and Ning Gu. (2011). What Architectural Historians Can Learn from Augmented Reality Technologies?. Proceedings of Electronic Visualisation and the Arts (EVA London 2011), BSC London 6-8 July 2011, 191-196.. 
Paterson, William. (1898) Lieut-Colonel Paterson's Journal and Discoveries at Hunter Rivers, in F.M Bladen, ed. Historical Records of New South Wales: Volume VI King and Bligh William Applegate Gullick, Government Printer, Sydney, 449

Portales, Cristina, Jose Luis Lerma, and Santiago Navarro. (2009) Augmented Reality and Photogrammetry: A Synergy to Visualize Physical and Virtual City Environments. ISPRS Journal of
Photogrammetry and Remote Sensing 65, no. 1, 3442.

Shortland, John, (1915) Letter to his Father in Commonwealth of Australia, ed. Historical Records of Australia: Volume V, July, 1804 - August, 1806 The Library Committee of the Commonwealth Parliament, Government Printers, Sydney, 481 